\title{
PSORIASIS UNCOVERED
}

Science is finally getting to grips with this enigmatic autoimmune disease. By James Mitchell Crow.

\section{SKIN DEEP}

Psoriasis is a non-contagious chronic skin disease affecting the keratinocytes, the cells that predominantly form the epidermis. During outbreaks of the disease, the keratinocytes proliferate at ten times the rate of non-diseased skin cells and fail to mature properly, resulting in raised, inflamed, scaly red skin lesions known as plaques, which can be itchy and painful.

T cell Macrophage

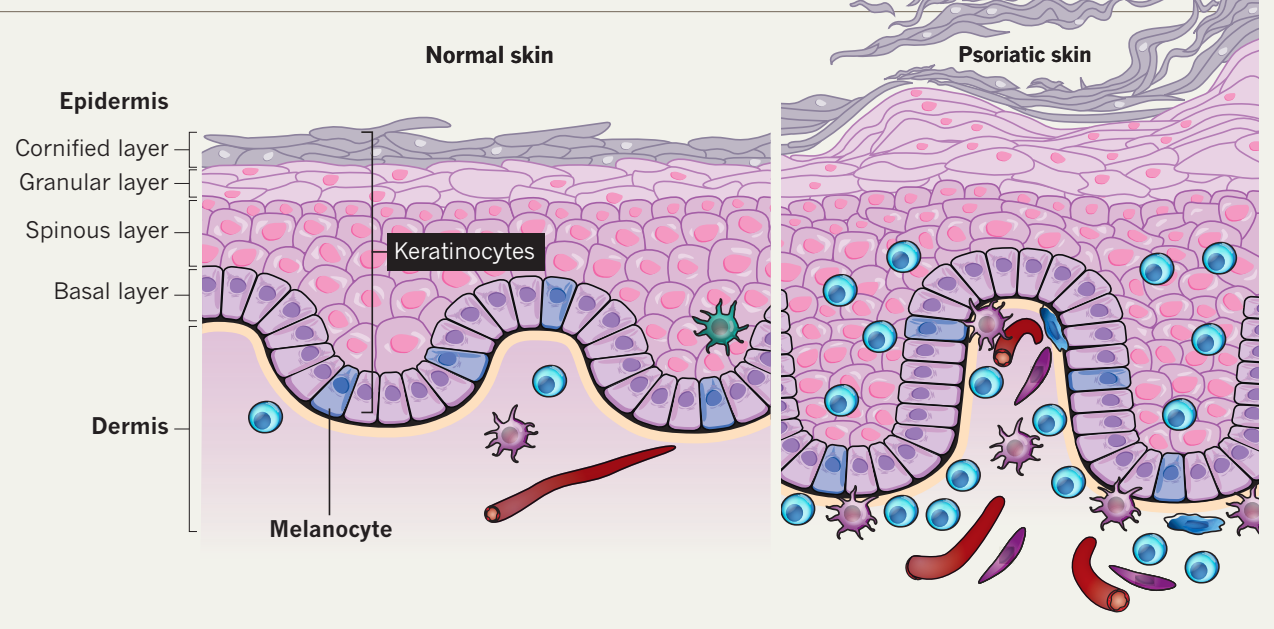

\section{AGE OF ONSET}

Although plaque psoriasis is considered a single disease, its severity, progression and response to treatment can vary markedly between patients - suggesting the existence of multiple underlying subtypes. For example, incidence data by age show two spikes, suggesting early- and late-onset forms of the disease.

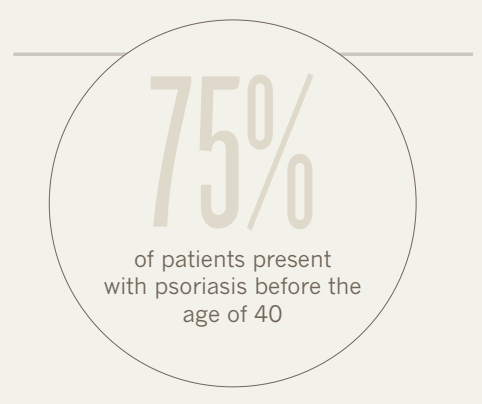

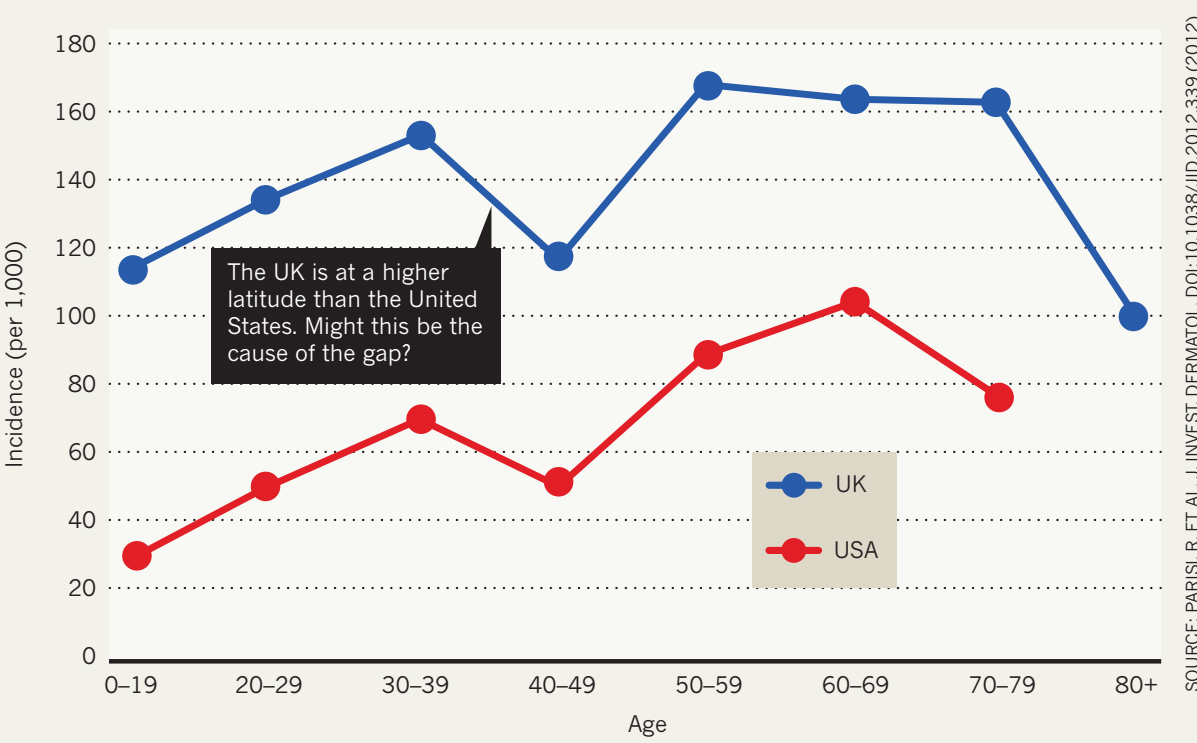

\section{TREATMENT}

A broad spectrum of therapies are available to treat psoriasis, depending on the severity of the disease. Newer biologic drugs are assessed by a 'PASI 75' score,

representing the percentage of patients achieving at least a $75 \%$ reduction in their Psoriasis Area and Severity Index (PASI). Despite considerable progress (see 'Silencing psoriasis', page S58), a cure remains elusive.
$>100$

\section{YEARS AGO}

COAL TAR

Tars have been

used for nearly

skin diseases. They

are often messy

and smelly, but

effective.
2,000 years to treat
1925

GOECKERMAN

THERAPY

A combination of

coal tar and

ultraviolet (UV)

irradiation. A

course of

treatment takes

several weeks,

and is now less

commonly used.
1951

CORTICOSTEROIDS

Very effective as

a short-term

treatment.

Unsuitable for

1950 s

long-term use

because of the growing risk of

side effects.
Safe and highly effective for chronic plaque psoriasis. In common use for many years before official FDA approval in 1972. 


\section{PSORIASIS IS COMMON}

Global epidemiological data are sparse.

There is a lack of uniformity of data

collection, so worldwide incidence and

prevalence are poorly documented.

Some trends do emerge - for example,

prevalence is higher closer to the poles.

A combination of genetic and

environmental factors are thought to be

behind this pattern.

Temperate (latitude above $40^{\circ}$ )

Subtropical $\left(23-40^{\circ}\right)$

Tropical $\left(<23^{\circ}\right)$

Study type

1 Point prevalence

2 Period prevalence

3 Lifetime prevalence

4 Not specified

Diagnostic method

A Dermatologist

B Physician

C Self-reported

\section{PSORIASIS IS HIGHLY HETEROGENEOUS}

Psoriasis comes in several distinct forms. Patients usually display a single form at any one time, although forms can coexist, and one form can be followed by another. Around $80 \%$ of psoriasis cases are classified as mild.

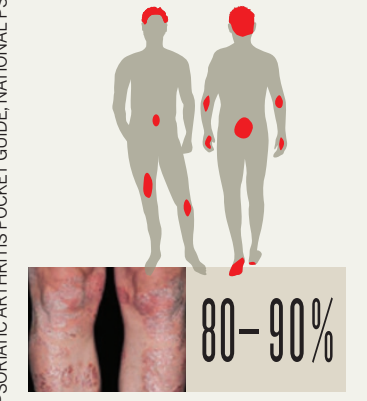

Chronic plaque psoriasis

Red, scaly plaques in

discrete patches. The

extent of body surface

area covered varies widely

from patient to patient.

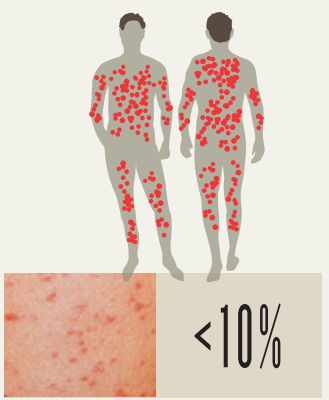

Guttate psoriasis

Multiple small,

red spots, usually

on the trunk and

limbs.

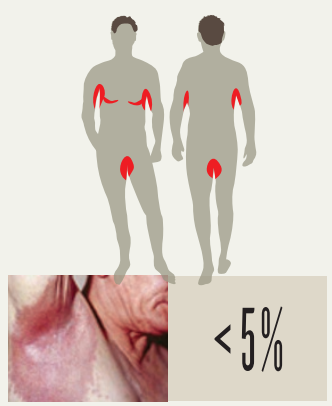

Inverse/flexural psoriasis

Very red scale-free lesions that form in skin folds.

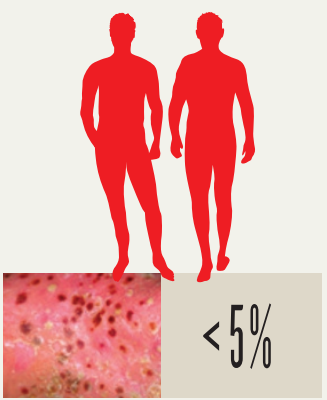

Pustular psoriasis

White blisters surrounded by red skin, which may be localized to a particular area, but which can also cover the whole body.

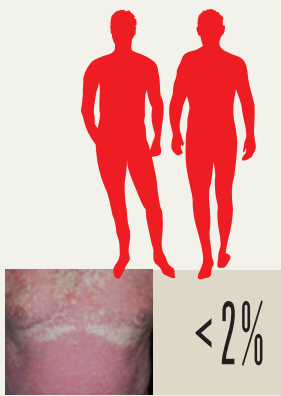

Erythrodermic psoriasis

Severe red inflammation and skin shedding covering most of the body. This is a rare but dangerous form of the disease that can cause patients to lose excessive amounts of heat through the skin.

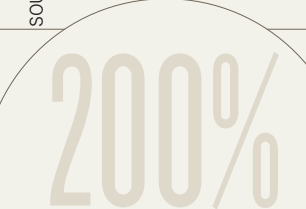

increased risk of a heart attack for a 30-yearold with severe psoriasis 1970s

\section{UVB LIGHT}

Can clear mild

cases of the disease.

PSORALEN AND UVA LIGHT (PUVA)

Possibly slightly more effective

although less

convenient, than

UVB therapy. A

second-line

treatment.

\section{6 \\ Alintill} generalized pustular and erythrodermic psoriasis, particularly in combination with UVB or PUVA therapy.

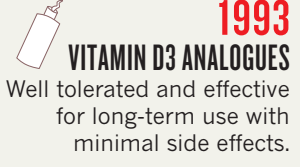

2006
REMICADE (INFLIXIMAB)
PASI 75 at 26
weeks: $50 \%$
2004
ENBREL (ETANERCEPT)
PASI 75 at 24 weeks:
$59 \%$
2003
AMEVIVE
(ALEFACEPT)
PASI 75 at 14
weeks: $21 \%$

$2.90 \%$

$2.84 \%$

$2.00 \%$

$2.00 \%$

$1.58 \%$

$1.52 \%$

$1.43 \%$

$1.40 \%$

$0.72 \%$

$0.70 \%$

$0.44 \%$

$0.23 \%$

$0.19 \%$

$0.12 \%$

$0.10 \%$

$0.00 \%$
2008 HUMIRA (ADALIMUMAB)

PASI 75 at 16 weeks: $71 \%$

\section{9 \\ STELARA (USTEKINUMAB)}

PASI 75 at 28 weeks:

$71-78 \%$ 